\title{
A Spatial Multi-criteria Decision Support System for Stress Recovery-Oriented Forest Management
}

\author{
Irene Capecchi, Gianluca Grilli, Elena Barbierato, and Sandro Sacchelli
}

\begin{abstract}
A solution to cope with chaotic urban settlements and frenetic everyday life is refuging in nature as a way to reduce stress. In general-in recent years-it has been scientifically demonstrated how natural areas are an important environment for psycho-physiological health. As a consequence, it is important to plan dedicated spaces for stress recovery in order to increase the well-being of people. With respect to forests, there is a growing interest in understanding the marketing and tourist potential of forest-therapy activities and policies. This paper develops a decision support system (DSS) for decision makers, based on geographic information system to define the suitability of forest areas to improve psychological and physiological human well-being. Innovative technologies such as electroencephalography (EEG) and virtual reality (VR) are applied to test human status. The DSS combines four sets of indicators in a multi-attribute decision analysis and identifies the areas with the largest stress-recovery potential. Two multi-attribute model—one in summer and one in winter - are elaborated to obtain a dynamic evaluation of suitability. Results show significant differences among forest type, forest management, altitude range, and season in terms of stand suitability. EEG and VR seem to be promising technologies in this research area. Strengths and weaknesses of the approach, as well as potential future improvement and implications for territorial marketing, are suggested.
\end{abstract}

Keywords Regional planning · Smart living - Territorial marketing • Socio-ecological dynamics $\cdot$ Ecosystem services

I. Capecchi · G. Grilli · E. Barbierato · S. Sacchelli $(\bowtie)$

Department of Agriculture, Food, Environment and Forestry, University of Florence, Florence, Italy

e-mail: sandro.sacchelli@unifi.it

I. Capecchi

e-mail: irene.capecchi@unifi.it

G. Grilli

Economic and Social Research Institute, Dublin, Ireland

Trinity College Dublin, Dublin, Ireland

(C) The Author(s) 2021

A. Bisello et al. (eds.), Smart and Sustainable Planning for Cities and Regions,

Green Energy and Technology, https://doi.org/10.1007/978-3-030-57764-3_12 


\section{Introduction}

There is an increasing trend for people to live far from natural environments, which is caused by urbanization and loss of green areas. This situation increases people's need to spend their free time in nature to recover from stressful city routines. A meta-analysis carried out by Bowler et al. (2010) found that all primary studies detected an association between health and exposure to natural environments, in particular with respect to stress relief. A Finnish study concluded that even shortterm visits to natural areas are beneficial to reduce perceived stress and cortisol levels (Tyrväinen et al. 2014). Forests play a central role with respect to stress recovery, in fact several studies show that spending time in forests has psychological and physiological benefits. Hansmann et al. (2007) detected positive effects of forest visits on self-assessed measures of well-being, headache, and stress. Other studies demonstrated that forest visits contributed to reduced cortisol levels, cerebral activity, and heart beat (Jin et al. 2010; Park et al. 2008). The positive effects of forests are now widely recognized, so that terms like "forest bathing" and "forest therapy" are often used to refer to restoration effects provided by forest visitation (Bielinis et al. 2018a, b; Ochiai et al. 2015; Ohe et al. 2017).

The emerging topic of stress relief supported by natural resources has gained interest in recent years. A typical "cultural ecosystem service" (CES) (MEA 2005) is characterized by a high degree of intangibility and incommensurability. In addition, the valuation, as well as quantification of CES, in dynamic environment such as forests suggests how standardized decision support systems (DSS) for provisioning of information for management are needed (Inostroza et al. 2017). Currently available DSS applied to CES are mainly focused on trade-off analysis among ecosystem services (including CES) and aesthetic/landscape perception. Pang et al. (2017) applied the Landscape Simulation and Ecological Assessment tool to assess synergies and trade-offs among provisioning of biomass for energy and timber production, forest carbon storage, recreation areas, and habitat networks. Dynamicity of economic value of ecosystem services throughout rotation period is considered in Sacchelli (2018) by means of Trade-off of Forest Ecosystem Services model. It considers raw material, carbon sequestration, habitat for species, and touristic and recreational value of Abies alba Mill. stand. The spatial dimension of CES are often explored: in this sense-among several DSS - participatory Geographic Information Systems (Brown and Fagerholm 2015), models applying social media (Langemeyer et al. 2018; Bernetti et al. 2019) or techniques based on a multi-method approach (Rovai et al. 2016; Saeidi et al. 2017) can be mentioned. While the association between forest visit and stress are extensively studied, to the best of the authors' knowledge it is still not clear whether forests are all equally effective or if some forest types are better than others for stress relief. Forests differ based on tree species and density and across seasons, therefore stress relief potential may also be different. Understanding which forests are suitable for therapy is useful information for forest management, as specific areas with high potential for forest therapy and stress recovery can be designed. In addition, the cited literature review lacks 
user-friendly and open-source DSS for dynamic stress-recovery assessment of forest areas. Within this framework, the aim of the work is to implement a spatial-based DSS centered on multicriteria analysis to provide information to forest managers about the perspective of stress-recovery-oriented forest management. The model will be able to classify forest compartments according to their suitability in CES provisioning for both winter and summer seasons. Innovative technologies such as electroencephalography (EEG) and virtual reality (VR) are applied to test psychological and physiological status of those interviewed. These techniques-as described in Sect. 2.3.1— seem to be promising in this research area.

The work is structured as follows. In the second section, we briefly describe the general framework of the study and the examined area, as well as methodology. The third section is dedicated to results and discussion of them. The final chapter suggests potential policy and practical implications of the method and offers additional conclusions.

\section{Material and Methods}

\subsection{General Framework}

The applied method provides a geographically-explicit DSS based on GRASS GIS v. 7.6 (https://grass.osgeo.org/) and multicriteria analysis. As reported by Comino et al. (2014), a multicriteria spatial DSS follows a flow of activities classifiable in three phases: (i) Intelligence, (ii) Design, and (iii) Choice. Specifically, "data acquisition, processing, and examining are done in the intelligence phase; formal modeling/GIS interaction in the design phase, in which a solution set of spatial decision alternatives are developed; and the choice phase involves the evaluation of alternatives" (Comino et al. 2014: 382-383) as described below. The DSS combines four criteria - each characterized by a set of indicators - in a multi-attribute decision analysis and identifies the areas with the largest stress recovery potential. The first criterion considers variables describing the degree of usability of the forest, while the second is dedicated to risk analysis for potential visitors. The third set considers psychological factors. Finally, the fourth set includes physiological features. Some indicators are computed for both summer and winter seasons to include dynamicity of CES. Each indicator is normalized in the range $0-1$ to be processed with the multiattribute technique. The normalization is based on a literature review if information was available; otherwise, a focus group involving researchers and local experts was carried out. For some indicators, normalization comes from laboratory experiments involving psychological and neuroscientific tests as subsequently described. Eventually, indicators are aggregated and constraints (mandatory conditions to be reached) are included in the analysis. 

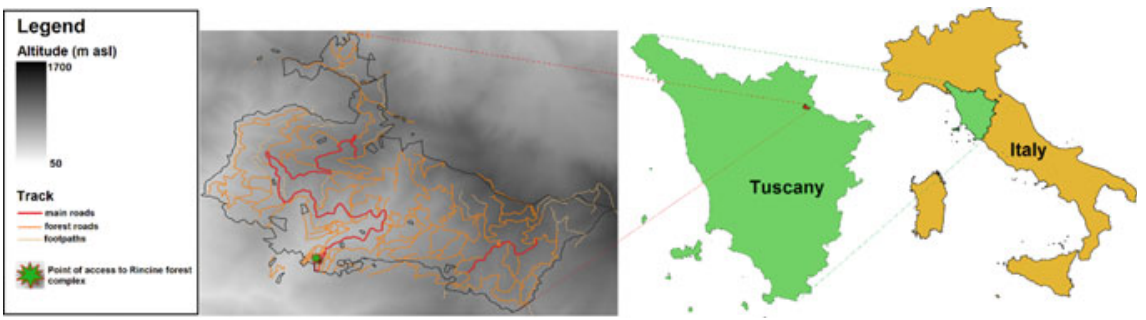

Fig. 1 Localization of study area

\subsection{Study Area and Territorial Informative System}

The case study is located in the Municipalities Union of Sieve and Arno Valleys (province of Florence, Tuscany region-Italy). Specifically, DSS is tested in the regional forest complex of Rincine (Fig. 1).

Rincine forests have a total extension of 1448 ha. This territory is currently the operational center of the Forestry Activities Service of the Municipalities Union. It is the site of numerous scientific researches and recently achieved the certification of international FSC ${ }^{\circledR}$ and PEFC ${ }^{\mathrm{TM}}$ standards. From a vegetation point of view, the prevailing forest typology is European beech ( $365 \mathrm{ha}$ ), followed by Turkey oak (290 ha) and artificial planted conifers (187 ha). Fifty-three percent of the woodland is managed as coppice; $47 \%$ are high forests.

The elaboration starts from the Territorial Informative System (TIS) reported in Table 1.

\subsection{Modellization}

\subsubsection{Identification of Criteria and Measurement}

All geodata are imported into GRASS GIS platform and-if vectorial-converted in raster format.

The criterion usability of forest includes four indicators: slope (\%, from DTM), accessibility and water uptake degree (derived from Rincine Forest Plan and experts' attribution as reported in TIS), as well as distance from access point. The latter parameter is computed by means of r.cost operation in GRASS GIS to quantify the cumulative distance from a starting point (preliminary set at point of access of Rincine forest complex) and one or more stop points (forest compartments). The distance-expressed in meters - is quantified considering a potential trail on main roads, forest roads, and footpaths. For each trail typology, a cost value (weight) is given to express the relative difficulty (time) in crossing the pixel. 
Table 1 Territorial informative system

\begin{tabular}{|c|c|c|}
\hline Variable & Format/value/(U.M.) & Source ${ }^{\mathrm{a}}$ \\
\hline Forest management & $\begin{array}{l}\text { Vectorial/high forest: } 1 \text {, coppice: } \\
2 \text {, no-forest: } 0\end{array}$ & Rincine forest plan \\
\hline Aspect & $\begin{array}{l}\text { Vectorial/N: 1, NE: 2, E: 3, SE: } \\
\text { 4, S: 5, SW: 6, W: 7, NW: } 8\end{array}$ & Rincine forest plan \\
\hline Stoniness & $\begin{array}{l}\text { Vectorial/absent: } 0 \text {, low: } 1,2 \text { : } \\
\text { medium, 3: high }\end{array}$ & Rincine forest plan \\
\hline Rockiness & $\begin{array}{l}\text { Vectorial/absent: } 0 \text {, low: } 1,2 \text { : } \\
\text { medium, 3: high }\end{array}$ & Rincine forest plan \\
\hline Flammability & $\begin{array}{l}\text { Vectorial/low: 1, 2: medium, } 3 \text { : } \\
\text { high }\end{array}$ & Rincine forest plan \\
\hline Accessibility & $\begin{array}{l}\text { Vectorial/0: not accessible, } 1 \text { : } \\
\text { easy, 2: medium, 3: difficulty }\end{array}$ & Rincine forest plan \\
\hline Water uptake & Vectorial/0: not easy, 1: easy & Rincine forest plan \\
\hline Ornithic richness & $\begin{array}{l}\text { Vectorial/1: medium, 2: high, 3: } \\
\text { very high }\end{array}$ & Rincine forest plan \\
\hline Forest density & $\begin{array}{l}\text { Vectorial/1: low, 2: medium, } 3 \text { : } \\
\text { high, 4: very high }\end{array}$ & Rincine forest plan \\
\hline Forest coverage & Vectorial/range $0-100 /(\%)$ & Rincine forest plan \\
\hline Tree height & Vectorial/top height/(m) & Rincine forest plan \\
\hline Broadleaf & Vectorial/range $0-100 /(\%)$ & Rincine forest plan \\
\hline Conifers & Vectorial/range $0-100 /(\%)$ & Rincine forest plan \\
\hline Forest function & Vectorial/1: protective, 2: other & Rincine forest plan \\
\hline Hydrogeological risk & $\begin{array}{l}\text { Vectorial/1: compartments at } \\
\text { risk }^{\mathrm{b}}, 0 \text { : no risk }\end{array}$ & Rincine forest plan \\
\hline Digital terrain model (DTM) & Raster/(m a.s.l.) & $\begin{array}{l}\text { Tuscany region opendata } \\
\text { (https://www502.regione.tos } \\
\text { cana.it/geoscopio/cartoteca. } \\
\text { html }\end{array}$ \\
\hline Forest roads & Vectorial & Rincine forest plan \\
\hline
\end{tabular}

${ }^{a}$ Variables from Rincine Forest Plan refer to compartments

${ }^{b}$ Hydrogeological risk is defined for compartments with medium or high risk for rockfall and/or landslide

The criterion risk for visitors is composed of two indicators: rockiness and flammability already described in the TIS. The hypothesis is that rockiness makes more difficult the walking capacity in forest compartments, increasing the risk of injury. Flammability depends on vegetational and climatic characteristics: its normalization is in fact evaluated for various seasonal conditions related to literature data.

The third criterion (psychological aspect) analyzes six indicators, i.e., ornithic richness, dendrometric variables (forest density, forest coverage, tree height), and other forest characteristics (forest management and percentage of broadleaf/conifers). The ornithic variable, and—specifically—species richness, is 
directly correlated to psychological improvement (Edwards et al. 2012). Dendrometric parameters have a more fluctuating trend. Their normalization derive from both the scientific literature and the focus group (Table 2). The importance of species categories (broadleaf and conifers) was analyzed in a laboratory experiment where interviewed were asked to indicate their willingness to visit (WTV) the forest in a VR environment. We used an HTC Vive headset, which provides the subjects a $360^{\circ}$ view and to be fully immersed in the place. Immersion is also emphasized using videos with audio. The use of VR has two main strengths: (i) it reduces the cost and time of questionnaire administration because all subjects can view the stimulus without needing to move outside; (ii) it removes time differences because the scene freezes at precise times, and all subjects can see the scenes in the same situation and weather conditions. The videos were recorded through a spherical camera (Nikon keymission 360). The urban video was recorded in a Florence suburb while the eight forest videos were recorded in a Rincine forest. The videos were recorded both in the winter season (at the end of February) during the vegetative-rest condition, and in the summer season (July) during vegetative conditions. The forest videos present four different forest types (Turkey Oak, Black pine, European Beech, and Douglas fir) and two different forest density (high and low). The sample is composed of selected subjects in the millennial generation who did not attend forestry science classes because this can alter the emotional perception of the forest. We interviewed 20 subjects (60\% female and $40 \%$ male), between 21 and 28 years of age and studying in the Territorial, Urban and Environmental Planning course of the University of Florence.

The sample was split into two gender-balanced sub-samples (T1 and T2) characterized by equal numbers of individuals. After viewing each 30 -s video, the subjects were queried concerning their WTV the place, based on a five-point Likert scale. To avoid distortion in responses due to different sequences, the order of videos (videos of urban scenes were also included to compare the effects of artificial vs. natural locations) was the following:

- T1: urban, Turkey oak (high density), black pine (low density), European beech (high density), Douglas fir (low density);

- T2: European beech (low density), Douglas fir (high density), Turkey oak (low density), black pine (high density), urban.

The entire survey takes approximately $15 \mathrm{~min}$. The questionnaire was administered in a neutral place (room) to guarantee both full immersion and reduction of potential external disturbances.

The last set of criteria (physiological responses) comprises three indicators: aspects of the forest compartments, the altitude, and EEG trends of the subjects of the lab experiment. Aspects and altitude are strictly related to climatic conditions, as well as the subjects' temperature perception of people. Thus local analysis and adaptation of literature are carried out to define the variables. Concerning EEG trends, the first step involves comparing subjects' stress level in forest and urban environments; the second step concerns analyses of stress levels in winter and summer season. The EEG equipment employed was the MUSE Brain, a wearable 
Table 2 Normalization of indicators and definition of constraints

\begin{tabular}{|c|c|c|}
\hline Indicator & Normalization & Source \\
\hline \multicolumn{3}{|l|}{ Criterion: usability } \\
\hline Slope & 1 & $\begin{array}{l}\text { Chiou et al. } \\
\text { (2010) }\end{array}$ \\
\hline & $\overrightarrow{40} \times$ & \\
\hline Accessibility & Value $1=1 ;$ value $2=0.66 ;$ value $3=0.33$ & Focus group \\
\hline $\begin{array}{l}\text { Distance from access } \\
\text { point }\end{array}$ & $1 \hat{1}$ & Focus group \\
\hline & $0 \quad 3000$ & \\
\hline Water uptake degree & Value $1=1 ;$ value $0=0.33$ & Focus group \\
\hline \multicolumn{3}{|c|}{ Criterion: risk for visitors } \\
\hline Rockiness & $\begin{array}{l}\text { Value } 0=1 ; \text { value } 1=0.66 ; \text { value } 2=0.33 ; \text { value } 3 \\
=0\end{array}$ & $\begin{array}{l}\text { Tomczyk } \\
(2011)\end{array}$ \\
\hline Flammability $^{\mathrm{a}}$ & $\begin{array}{l}\text { Summer scenario: value } 1=1 ; \text { value } 2=0.66 \text {; value } \\
3=0.33 \\
\text { Winter scenario: all value }=1\end{array}$ & $\begin{array}{l}\text { Tomczyk } \\
\text { (2011) }\end{array}$ \\
\hline \multicolumn{3}{|l|}{ Criterion: psychological } \\
\hline Ornithic richness & Value $3=1 ;$ value $2=0.75 ;$ value $1=0.5$ & $\begin{array}{l}\text { Edwards } \\
\text { et al. (2012) }\end{array}$ \\
\hline Forest management & Value $1=1 ;$ value $2=0.5$ & $\begin{array}{l}\text { Riccioli et al. } \\
(2019) ; \\
\text { Focus group }\end{array}$ \\
\hline Forest density & $\begin{array}{l}\text { Value } 1=0.5 ; \text { value } 2=0.75 ; \text { value } 3=1 ; \text { value } 4= \\
0.5\end{array}$ & $\begin{array}{l}\text { Pelyukh et al. } \\
\text { (2019), } \\
\text { Chiang et al. } \\
\text { (2017) }\end{array}$ \\
\hline Forest coverage & $\begin{array}{l}\text { Linear normalization on maximum value according to } \\
\text { the following formula: } \\
N_{i}=\left(\max _{m}-v_{i}\right) /\left(\max _{m}-\min _{m}\right) \\
\text { where } \max _{m} \text { and } \min _{m} \text { are respectively maximum and } \\
\text { minimum value in the map, } v_{i} \text { is the value for the } \\
\text { pixel } i \text { th }\end{array}$ & Focus group \\
\hline Top height & $\begin{array}{l}\text { Linear normalization on maximum value according to } \\
\text { the following formula: } \\
N_{i}=\left(\max _{m}-v_{i}\right) /\left(\max _{m}-\min _{m}\right) \\
\text { where } \max _{m} \text { and } \min _{m} \text { are respectively maximum and } \\
\text { minimum value in the map, } v_{i} \text { is the value for the } \\
\text { pixel } i \text { th }\end{array}$ & Focus group \\
\hline
\end{tabular}


Table 2 (continued)

\begin{tabular}{|c|c|c|}
\hline Indicator & Normalization & Source \\
\hline WIllingness to visit ${ }^{\mathrm{a}}$ & $\begin{array}{l}\text { Summer scenario: if broadleaf }=1 ; \text { if conifers }=0.73 \\
\text { Winter scenario: if broadleaf }=0.59 ; \text { if conifers }= \\
0.78 \text { (weighted on broadleaf/conifers percentage) }\end{array}$ & $\begin{array}{l}\text { Laboratory } \\
\text { experiment }\end{array}$ \\
\hline \multicolumn{3}{|l|}{ Criterion: physiological } \\
\hline Aspect & $\underbrace{1 \uparrow}_{12345678}$ & Focus group \\
\hline Altitude $^{\mathrm{a}}$ & 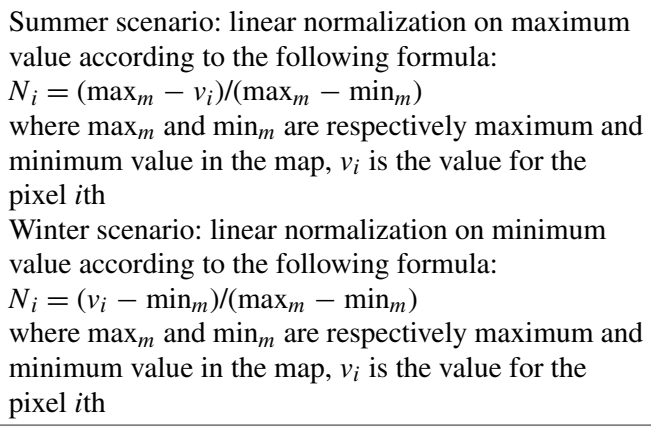 & $\begin{array}{l}\text { Boori et al. } \\
(2015)\end{array}$ \\
\hline $\begin{array}{l}\text { Electroencephalographic } \\
\text { trend }^{\mathrm{a}}\end{array}$ & $\begin{array}{l}\text { Summer scenario: if broadleaf }=0.96 \text {; if conifers }=1 \\
\text { Winter scenario: if broadleaf }=0.85 ; \text { if conifers }= \\
0.87 \\
\text { (weighted on broadleaf/conifers percentage) }\end{array}$ & $\begin{array}{l}\text { Triguero-Mas } \\
\text { et al. (2017); } \\
\text { Laboratory } \\
\text { experiment }\end{array}$ \\
\hline Constraints & Definition & Source \\
\hline Forest area & If forest management is 0 , then $=0,1$ otherwise & Focus group \\
\hline Accessibility & If accessibility is 0 , then $=0,1$ otherwise & Focus group \\
\hline Forest function & If forest function is 1 , then $=0,1$ otherwise & Focus group \\
\hline Hydrogeological risk & If hydrogeological risk is 1 , then $=0,1$ otherwise & Focus group \\
\hline
\end{tabular}

${ }^{a}$ indicators with summer and winter scenario

four-channel EEG, which measures brain activity. This device analyzes signals from four electrodes [TP9, AF7, AF8, TP10 scalp positions according to a 10-20 system classification (Klem et al. 1999)] located in the frontal and temporal lobes of the brain. The outputs of MUSE Brain are raw EEG data, raw accelerometer, raw Fast Fourier Transformation (FFT) coefficients, relative, and absolute band powers for waves and blink-and-jaw-clench detection that can be re-elaborated with available algorithm for several platforms (R-cran, Matlab). Five waves (measured in hertz) are derived from outputs: alpha, beta, theta, gamma, and delta. Each wave or the combinations among them can be related to the emotional status of individual (Norwood et al. 2019). Beta waves are generally associated with awake people in a condition 
to alert consciousness, thinking, and excitement. On the other hand, alpha waves are considered as a proxy of physically and mentally relaxed status. In the case study, as done in previous scientific works (Sacchelli et al. 2020), we concentrated on beta waves because they are more reactive to short videos, while alpha is more sensitive to the dose-response effect (Chiang et al. 2017). The time series of beta waves were compared using ANOVA and OLS regression to identify statistically significant differences originated from different forest types.

\subsubsection{Normalization of Criteria}

Indicators were normalized as reported in Table 2. Suitable areas for stress-recovery in all indicators have value 1; the value decreases to zero in a non-suitable area. Normalization is developed through fuzzy logic by means of both functions (Cheng 1999) and a linguistic evaluator (Chen and Hwang 1992). The aggregation of indicators is performed as total compensatory approach (i.e., average of normalized value). Constraints were included as Boolean factors (Table 2) to be aggregated at suitability maps with logic operator "AND” (Larson et al. 1991).

\section{Results and Discussion}

Results are elaborated through zonal statistics operation to compute an average suitability score at the Rincine forest-complex level, and for different variables. The stress recovery potential is assessed for summer and winter seasons separately.

The average score for the total forest surface in the district is 0.56 in summer and 0.59 in winter. This difference is probably caused by the absence of weights in the multicriterial model. In particular, the flammability indicator seems to negatively affect the summer scenario more than other indicators, due to the higher probability of fires.

Table 3 reports average scores for forest type and forest management.

The deciduous category has a lower suitability value than conifers, in particular in winter time, when the gap increases. That assertion highlights the importance of usability and psychological criteria for the comparison of broadleaf and conifer forests. In fact, dendrometric, managerial, and logistic characteristics of compartments as well as the WTV the forest could represent influential indicators. Conifers

Table 3 Average suitability scores for forest variables and season

\begin{tabular}{l|l|l|l}
\hline & & Summer & Winter \\
\hline \multirow{2}{*}{ Forest type } & Broadleaf & 0.50 & 0.52 \\
\cline { 2 - 4 } & Conifers & 0.66 & 0.74 \\
\hline \multirow{2}{*}{ Forest management } & High forests & 0.65 & 0.71 \\
\cline { 2 - 4 } & Coppices & 0.48 & 0.49 \\
\hline
\end{tabular}


are generally higher than deciduous stands, and they can be more accessible because they can be part of reforestation process (mainly adopted-in the case study areanear to roads). In summer, WTV is higher in broadleaf stands due to vegetative conditions and subsequent positive perception. Eventually, coppices are perceived worse than high forests, and this aspect has a negative (average) repercussion on broadleaf evaluation.

An interesting suitability trend is highlighted for the altitude range (Fig. 2). The value is indirectly proportional to altitude in both winter and summer. The usability criterion influences the suitability trend because higher altitudes are characterized by longer walking distances and steeper slopes. In summer the average suitability tends to be greater than in winter for the importance of physiological criterion.

A final aspect to stress is the appropriateness of DSS for visualization and presentation of results to the various stakeholders. In this respect, Fig. 3 shows the main output of the DSS model, i.e., a suitability map with scores for each forest parcel. This map may be the starting point for forest management that aims at maximizing the stress-recovery potential of local forested areas.

The research into natural areas for stress recovery has led to the creation of healing gardens inside hospital open areas and to nature-based activities to help solve neural

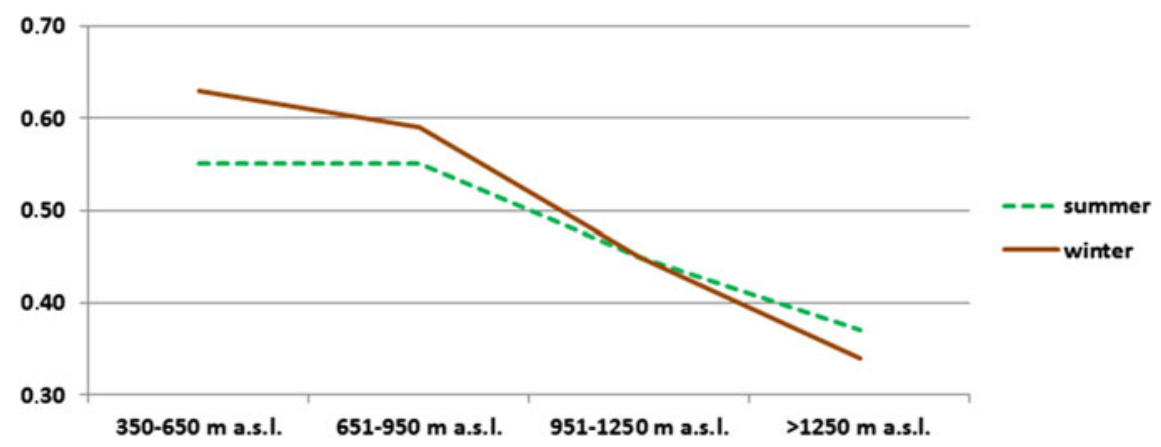

Fig. 2 Suitability score (0-1) based on altitude range in summer and winter
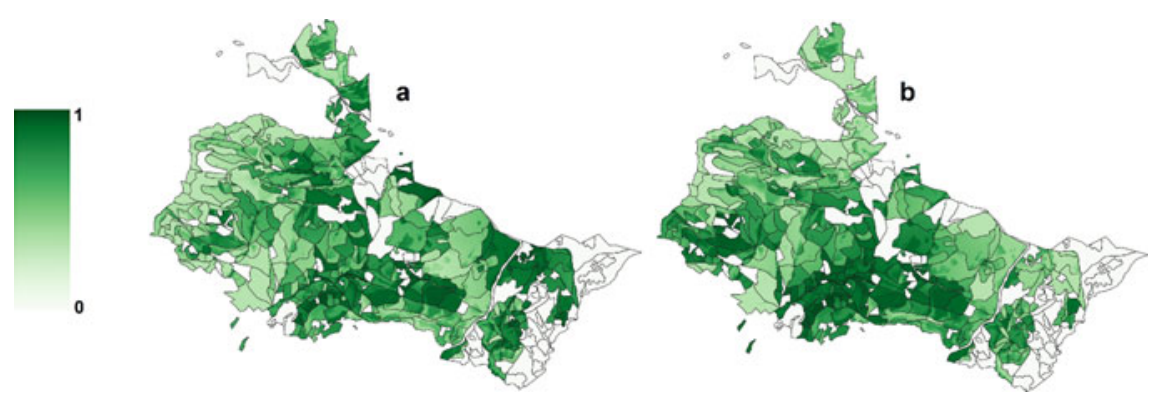

Fig. 3 Suitability score (0-1) in summer (a) and winter (b) at compartment level 
problems, such as horticultural therapies (Cervinka et al. 2012; Jiang 2014). However, reproduced natural environments are not as effective as wild natural ones. In Nordic countries, in fact, it was found that the sounds of nature are associated with increased levels of restoration and well-being, which can hardly be reproduced in hospital gardens (Konu et al. 2017). For this reason, therapy-oriented management of forests is very important to provide spaces for individuals seeking restoration.

\section{Conclusions}

The present study follows recent trends in natural-resource management that highlight how natural environments are very effective for stress recovery and for the general psycho-physiological health of individuals. Dedicated spaces for stress recovery increase the well-being of people and a territorial balance between urban and natural environments; as a consequence, larger recreational opportunities are beneficial for marketing, in terms of increased numbers of potential tourist segments to attract, and for their potential spillovers to local economies. The literature suggests that people do not exhibit a unique response to all natural settings, but some environments are more effective than others for restoration.

Within this framework, the paper provides a geographically explicit DSS that could assist decision makers in planning dedicated forest areas for stress recovery. The DSS applies a user-friendly approach based on multi-criteria analysis. The inclusion of people's psychological and physiological responses to different forest types and density represents a novelty within the forest DSS literature. New technologies such as EEG, VR, and the combination of their results in a spatial model furnish more insight in respect to currently available techniques. Results confirm that all forest types provided lower stress levels compared to the urban environment. In addition, effectiveness of forest for well-being improvement is strongly affected by the season, suggesting how the temporal variable must be taken into account for a correct valuation of the topic.

Future development of DSS should be focused on the application of weights to criteria or indicators to balance local peculiarities and stakeholders' perceptions. In this sense, sensitivity analyses (e.g., "what-if" scenario) based on variation of weight should be developed to validate the results (Capolongo et al. 2019). An integration of physiological indicator could be performed that considers not only EEG responses to various stimuli but also additional parameters (e.g., heart rate, blood pressure, salivary cortisol). Outputs of the model can be easily presented to policy-and decision makers to create a basis for future marketing-oriented local activities for stress relief and human well-being.

Acknowledgements This study was conducted in the frame of the "Pianificazione strategica di impresa per la valorizzazione sostenibile delle filiere e dei servizi ecosistemici forestali" project, co-financed by Fondazione Cassa di Risparmio di Firenze. 
The authors would like to thank A. Ventre and I. Battaglini for their valuable help in field investigations.

\section{References}

Bernetti I, Chirici G, Sacchelli S (2019) Big data and evaluation of cultural ecosystem services: an analysis based on geotagged photographs from social media in Tuscan forest (Italy). iForest 12:98-105

Bielinis E, Omelan A, Boiko S, Bielinis L (2018a) The restorative effect of staying in a broad-leaved forest on healthy young adults in winter and spring. Baltic For 24:218-227

Bielinis E, Takayama N, Boiko S, Omelan A, Bielinis L (2018b) The effect of winter forest bathing on psychological relaxation of young Polish adults. Urban For Urban Greening 29:276-283

Boori MS, Vozenìlek V, Choudhary K (2015) Land use/cover disturbance due to tourism in Jesenìky Mountain, Czech Republic: a remote sensing and GIS based approach. Egypt J Remote Sens Space Sci 18:17-26

Bowler DE, Buyung-ali LM, Knight TM, Pullin AS (2010) A systematic review of evidence for the added benefits to health of exposure to natural environments. BMC Public Health 10:456

Brown G, Fagerholm N (2015) Empirical PPGIS/PGIS mapping of ecosystem services: a review and evaluation. Ecosyst Serv 13:119-133

Capolongo S, Sdino L, Dell'Ovo M, Moioli R, Della Torre S (2019) How to assess urban regeneration proposals by considering conflicting values. Sustainability 11:3877

Cervinka R, Röderer K, Hefler E (2012) Are nature lovers happy? On various indicators of wellbeing and connectedness with nature. J Health Psychol 17(3):379-388. https://doi.org/10.1177/ 1359105311416873

Chen SJ, Hwang CL (1992) Fuzzy multiple attribute decision making: methods and applications. Springer, Berlin

Cheng CH (1999) A simple fuzzy group decision making method. In: Fuzzy systems conference proceedings, vol 2, Seoul, Korea, pp 910-915

Chiang YC, Li D, Jane HA (2017) Wild or tended nature? The effects of landscape location and vegetation density on physiological and psychological responses. Landscape Urban Plann 167:72-83

Chiou CR, Tsai WL, Leung YF (2010) A GIS-dynamic segmentation approach to planning travel routes on forest trail networks in Central Taiwan. Landscape Urban Plan 97:221-228

Comino E, Bottero M, Pomarico S, Rosso M (2014) Exploring the environmental value of ecosystem services for a river basin through a spatial multicriteria analysis. Land Use Policy 36:381-395

Edwards DM, Jay M, Jensen FS, Lucas B, Marzano M, Montagné C, Peace A (2012) Public preferences across Europe for different forest stand types as sites. Ecol Soc 17(1):27

Hansmann R, Hug S, Seeland K (2007) Restoration and stress relief through physical activities in forests and parks. Urban For Urban Greening 6:213-225. https://doi.org/10.1016/j.ufug.2007. 08.004

Inostroza L, König HJ, Pickard B, Zhen L (2017) Putting ecosystem services into practice: trade-off assessment tools, indicators and decision support systems. Ecosyst Serv 26(Part B):303-305

Jiang S (2014) Therapeutic landscapes and healing gardens: a review of Chinese literature in relation to the studies in western countries. Front Architectural Res 3(2):141-153. https://doi.org/10.1016/ j.foar.2013.12.002

Klem GH, Lüders HO, Jasper HH, Elger C (1999) The ten-twenty electrode system of the international federation. Electroencephalogr Clin Neurophysiol 52:3-6

Konu H, Komppula R, Vikman N (2017) Listening to the sounds of silence: forest based wellbeing tourism in Finland. In: Chen J, Prebensen N (eds) Nature tourism, chap 11. Routledge, London. https://doi.org/10.4324/9781315659640 
Langemeyer J, Calcagni F, Baró F (2018) Mapping the intangible: using geolocated social media data to examine landscape aesthetics. Land Use Policy 77:542-552

Larson M, Shapiro M, Tweddale S (1991) Performing map calculations on GRASS data: r.mapcalc program tutorial. U.S. Army Corps of Engineers, Construction Engineering Research Laboratory. https://grass.osgeo.org/uploads/grass/history_docs/mapcalc.pdf

MEA, Millennium Ecosystem Assessment (2005) Ecosystems and human well-being: synthesis. Island Press, Washington, DC

Norwood MF, Lakhani A, Maujean A, Zeeman H, Creux O, Kendall E (2019) Brain activity, underlying mood and the environment: a systematic review. J Environ Psychol 65:101321

Ochiai H, Ikei H, Song C, Kobayashi M, Miura T, Kagawa T, Li Q, Kumeda S, Imai M, Miyazaki Y (2015) Physiological and psychological effects of a forest therapy program on middle-aged females. Int J Environ Res Public Health 12:15222-15232

Ohe Y, Ikei H, Song C, Miyazaki Y (2017) Evaluating the relaxation effects of emerging foresttherapy tourism: a multidisciplinary approach. Tourism Manage 62:322-334. https://doi.org/10. 1016/j.tourman.2017.04.010

Pang X, Nordström EM, Böttcher H, Trubins R, Mörtberg U (2017) Trade-offs and synergies among ecosystem services under different forest management scenarios- the LEcA tool. Ecosyst Serv 28(Part A):67-79

Park B, Tsunetsugu Y, Ishii H, Furuhashi S, Hirano H, Kagawa T, Miyazaki Y (2008) Physiological effects of Shinrin-yoku (taking in the atmosphere of the forest) in a mixed forest in Shinano Town, Japan. Scand J For Res 23(3):278-283. https://doi.org/10.1080/02827580802055978

Park BJ, Tsunetsugu Y, Kasetani T, Kagawa T, Miyazaki Y (2010) The physiological effects of Shinrin-yoku (taking in the forest atmosphere or forest bathing): evidence from field experiments in 24 forests across Japan. Environ Health Prev Med 15(1):18-26. https://doi.org/10.1007/s12 199-009-0086-9

Pelyukh O, Paletto A, Zahvoyska L (2019) Comparison between people's perceptions and preferences towards forest stand characteristics in Italy and Ukraine. Ann Silvicultural Res 43(1):4-14

Riccioli F, Fratini R, Marone E, Fagarazzi C, Calderisi M, Brunialti G (2019) Indicators of sustainable forest management to evaluate the socio-economic functions of coppice in Tuscany, Italy. Socio-Econ Plann Sci 70:100732

Rovai M, Andreoli M, Gorelli S, Jussila H (2016) A DSS model for the governance of sustainable rural landscape: a first application to the cultural landscape of Orcia Valley (Tuscany, Italy). Land Use Policy 56:217-237

Sacchelli S (2018) A decision support system for trade-off analysis and dynamic evaluation of forest ecosystem services. iForest 11:171-180

Sacchelli S, Grilli G, Capecchi I, Bambi L, Barbierato E, Borghini T (2020) Neuroscience application for the analysis of cultural ecosystem services related to stress relief in forest. Forests 11:190. https://doi.org/10.3390/f11020190

Saeidi S, Mohammadzadeh M, Salmanmahiny A, Mirkarimi SH (2017) Performance evaluation of multiple methods for landscape aesthetic suitability mapping: a comparative study between multi-criteria evaluation, logistic regression and multi-layer perceptron neural network. Land Use Policy 67:1-12

Tomczyk AM (2011) A GIS assessment and modelling of environmental sensitivity of recreational trails: the case of Gorce National Park, Poland. Appl Geogr 31:339-351

Triguero-Mas M, Gidlow CJ, Martínez D, de Bont J, Carrasco-Turigas G, Martínez-Íñiguez T, Hurst G, Masterson D, Donaire-Gonzalez D, Seto E, Jones MV, Nieuwenhuijsen MJ (2017) The effect of randomised exposure to different types of natural outdoor environments compared to exposure to an urban environment on people with indications of psychological distress in Catalonia. PLoS ONE 12:e0172200

Tyrväinen L, Ojala A, Korpela K, Lanki T, Tsunetsugu Y (2014) The influence of urban green environments on stress relief measures: a field experiment. J Environ Psychol 38:1-9. https://doi. org/10.1016/j.jenvp.2013.12.005 
Open Access This chapter is licensed under the terms of the Creative Commons Attribution 4.0 International License (http://creativecommons.org/licenses/by/4.0/), which permits use, sharing, adaptation, distribution and reproduction in any medium or format, as long as you give appropriate credit to the original author(s) and the source, provide a link to the Creative Commons license and indicate if changes were made.

The images or other third party material in this chapter are included in the chapter's Creative Commons license, unless indicated otherwise in a credit line to the material. If material is not included in the chapter's Creative Commons license and your intended use is not permitted by statutory regulation or exceeds the permitted use, you will need to obtain permission directly from the copyright holder.

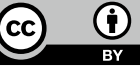

